\title{
La Obra y la Personalidad de Giovanni Papini
}

\author{
Por EnRique Barboza
}

En el siglo XIX, el positivismo había extendido su dominio por toda Europa y por supuesto, había logrado una situación preponderante en Italia. Se recuerda al eminente profesor Roberto Ardigó, sacerdote que dejó los hábitos impulsado por una especie de apostolado laico y positivista.

Contra tal corriente de ideas, que tuvo también un importante reflejo en la literatura, el naturalismo, se inició una reacción finisecular en la Península. En el campo estrictamente filosófico, surgió el neo-hegelianismo, con Bertrando Spaventa y más tarde con Croce $\mathrm{Y}$ Gentile. En el campo más vasto, literario $\mathrm{y}$ artístico, se iniciaron tres movimientos importantes: el modernismo, literario y religioso, evidente eco de Eoisy", cuya expresión más importante es la obra de Fogazzaro; el estetismo de D'Anunzio, afrancesado $\mathrm{y}$ en cierto modo pagano, con fuertes exaltaciones patrióticas; y el futurismo, a cuya cabeza apareció el poeta Marinetti, al que apareció transitoriamente vinculado Papini.

Menos detonante que el futurismo, pero quizás más efectivo, aunque carente de una técnica de coordinación disciplinaria, fue, a principios de siglo, el movimiento iniciado por Papini en su revista Leonardo, que llegó a ser uno de los órganos de lucha contra el positivismo y de exaltación de los valores del espíritu. Desde allí, divulgó Papini el intuicionismo bergsoniano y el pragmatismo norteamericano de Peirce y James.

En Uomo finito, uno de sus libros más bellos y emocionantes, cuenta las incidencias de la aparición del Leonardo, el 4 de Enero de 1903. "Comenzó de ocho páginas. Hablaba de todo (incluso de política), pero más de arte que de filosofía, y la filoso- 
fía tenía un aspecto tan lírico, fantasioso y bizarro, que no parecía ya serlo. Después de algunos meses, los artistas y literatos comenzaron a no pagar más, a no trabajar más... Hacia el verano quedamos solos dos filósofos: yo y Giuliano (Giuliano era Prezzolini). El periódico se volvió revista... El arte se puso a un lado; la literatura y al política fueron expulsadas y la filosofía se volvió dueña y señora dominadora. Una filosofía a nuestro modo, que se contraponía a la tradicional, a la de los manuales, a la de los profesores y de las universidades. Queríamos cambiar la idea misma de la filosofía y dar al pensamiento las imágenes y el vuelo de la poesía... Y poner en la poesía de los literatos un fermento de pensamiento. Había sido hasta entonces racional y nosotros combatíamos con todas las fuerzas el intelectualismo. Había sido siempre contemplativa, y se quería que se volviese creadora y que tomase su parte en la obra de rehacer el mundo". Cinco años duró el Leonardo. Papini lo recuerda. "Era en pleno verano, Agosto. El último número se publicó con un haz de atroces saetas y con la cubierta color de sangre; pero era triste y pesado como el féretro de un amante asesinado".

Después escribió en La Voce, de Prezzolini, de orientación idealista, en relación con Croce y Gentile; y escribió también en el Regno de Corradini del que Papini fué redactor; y en el Hermes de Borghese. Finalmente, fundó Lacerba (1913-1915), dirigida con Soffici, tribuna de exaltada renovación, que preparó el ambiente para la alianza con el futurismo. Cuando Italia entró en la primera Guerra, el grupo de escritores florentinos se dispersó.

En la ola del Futurismo se hace más visible y eficaz el ingenio de Papini. Si el modernismo trata de conciliar la ciencia con la religión y el estetismo considera que el arte debe dar sentido a la vida, el futurismo es una especie de romanticismo del futuro. Fuertemente iconoclasta, no permitía que quedara en pie ni un recuerdo, ni una brizna del depresivo pasado. Así explica Papini su incorporación a la nueva corriente estética y cultural. "Soy futurista, porque futurismo significa libertad absoluta; porque significa aceptación completa de la civilización moderna, con todas sus maravillas gigantescas; porque estoy cansado de los viejos metros, de las nenias, de las cadencias, de los ritornelli de nuestros padres, abuelos y bisabuelos y progenitores; porque estoy harto de los idilios cretinos, de los sentimentalismos de muñecos; de la falsa profundidad... Soy futurista, porque sé que 
la demasiada cultura osifica el cerebro, diseca las venas, acrecienta la incertidumbre y arruina el temperamento... Soy futurista, porque adoración exagerada del glorioso pasado, de las épocas áureas y de la eterna inmortal academia de las mil trampas, envilece el alma, refrena la impresión y acaba esterilizando a los pueblos... Soy futurista, porque futurismo significa Italia -una Italia más grande que la pasada, más moderna, más adelantada que las demás naciones".

Cuando Papini se vinculó al futurismo, había escrito ya un buen número de libros, entre otros: II Tragico Quotidiano, II Ptlota Ciecco (1907), Parole e Sangue (1912), Buffonate (1914), Venticuattro Cervelli (1912); pero ninguna tuvo la resonancia de su Crepúscolo dei fllosofi y Uomo Finito.

La inquietud intelectual de Papini lo indujo a volcar su pasión en el campo de la filosofía. El resultado fué El Crepúsculo de los Filósofos, publicado cuando sólo tenía 25 años, libro en el cual define su posición antifilosófica. La primera edición es de 1906. Este libro - dice Papini- no es un libro de buena fe. Es un libro de pasión, y por tanto de injusticia - un libro desigual, parcial, sin escrúpulos, violento, contradictorio, insolente como todos los libros de los que aman y odian y no se avergüenzan de sus amores ni de sus odios. Luego afirma que es una obra de vida. Son fragmentos de mi liberación intelectual. Dios, en otra parte: Es un proceso a la filosofía, es un esfuerzo por demostrar la vanidad, la vacuidad y la ridiculez de lá filosofía. He querido, en una palabra, hacer una liquidación general de este equívoco aborto del espíritu humano. Llama a la filosofía monstruo de sexo dudoso que no quiere ser ni ciencia ni arte y es una mezcla de las dos, sin llegar a ser un instrumento de acción y conquista. Este libro, dice, es una "masacre", un "macello", un "estrago", un "matadero público"... Para qué seguir.

La primera víctima es Manuel Kant, "un burgués honesto y ordenado", es decir un mediocre, sin sentido de las cosas grandes. No ve otra cosa que la moral cristiana y la mecánica de Newton. Fuera de la filosofía, es un perfecto filisteo que bebe cerveza con negociantes, riendo de las historias del día y calculando cuantas onzas debe comer y cuantos minutos debe pasear. Habla de estética sin conocer a Shakespeare, jamás ha visitado una galería de cuadros y prefiere a toda música la banda militar. Enseña geografía, pero no ha salido a más de diez millas de 
Koenigsberg. Tiene en gran estima el sentimiento, pero no quiere tener relaciones por muchos años con las hermanas pobres. Pero eso sí, es rígidamente moral y pedantescamente ordenado. Es sumamente orgulloso. Se parangonaba con Copérnico y le agradaba que sus admiradores le llamaran nuevo Cristo y nuevo Sócrates.

$\mathrm{Su}$ problema se reduce a esto: salvar la vida del mal y la ciencia del escepticismo. Elabora una ética y una gnoseología. Papini hace ver que la ética precede a la gnoseología; lo contrario de lo que dicen los manuales.

Experto conciliador, salva el fenómeno, o sea el determinismo, con su gnoseología; pero al mismo tiempo salva la libertad con su teoría del noumeno. Salva el sensismo de los empiristas - con su teoría de la materia-; y el innatismo de los racionalistas - con su teoría de la forma a priori. En el campo moral, necesitaba estar de acuerdo con el Evangelio y al mismo tiempo con la ciencia. Por eso necesitaba, cutonomía, universalidad y necesidad. Puesto fuera el Hedonismo y el interés, lo mismo que todo fin individual, la buena voluntad debe seguir un orden racional, interno. El principio de la buena voluntad es el imperativo categórico, que es universal, porque deriva de la razón. Papini afirma con agudeza que Kant se propuso hacer una moral racional y le resultó sentimental, porque le resultó una moral "altruística", porque pone el deber de cumplir lo que todos los otros pueden cumplir, y" por consecuencid ln hacer gdos otros lo que, hecho por los otros, podría hacernos daño. Es el consejo de Cristo, pasado a través de un "newtoniano tudesco". En suma, el apriori es artificial; el noumeno es contradictorio, $y$ todo el edificio cae como un castillo de naipes; porque todo no es sino "palabras..."

Hegel es el homo duplex. Tiene dos almas: el profesor filisteo y el poeta romántico. Kant es un burgués. Hegel es un burgués y es un romántico. En sus libros pone de todo, habla de todo, explica todo, como un parvenu de la cultura que muestre sus tesoros. "Lo que lo salva es el Hegel del romanticismo. Hegel es un romántico que quiere salir del romanticismo. Quiere tener la verdad completa, absoluta. "Para hacer esto, basta con poner dentro de ella también el error... Así el error se vuelve un momento de la verdad. Para conciliar lo verdadero con lo falso, hay un obstáculo: la contradicción, Hegel cabalga en el de- 
venir, caballo encantado que conoce otros obstáculos. Sin más, transforma el ser en pensamiento, lo real en racional, y viceversa. Si ponemos la razón en el fondo de todo, es posible hacer con el mundo nuestra voluntad.

Para salir del romanticismo, Hegel necesitaba usar medios, románticos. Es romántica la conciliación de los contradictorios, el contraste entre el yo y el mundo, entre el genio y las leyes... "Sus libros no son aventuras metafísicas o poemas caballerescos del espíritu, donde lo absoluto, como el héroe invisible, aparece y desaparece, muere y resurge, como un caballero encantado o como un mago ultrapotente? Su filosofía no tiene aspectos medioevales, no es prevalentemente lógica como la escolástica, unitaria como el catolicismo, absolutista como el feudalismo? Sus libros no son como catedrales góticas, profundas, oscuras, altas, complicadas, más bien que templos paganos, simples y abiertos al sol?.

Para Hegel la Idea es todo; y ¿qué es la idea? En realidad, no puede comprenderse, es lo incomprensible, porque es todo. La Idea es el pensamiento y es la naturaleza. En vez de ser esto claro, es oscuro. Pero H.- dice Papini, es como los gatos: ve mejor en la oscuridad. Hay una marcha triunfal de la idea: el inicio es la identidad originaria entre el ser y el no ser. El ser, que es el concepto más simple y más abstracto, es idéntico al no ser, que es su contrario, $y$ que siendo su contrario, es también su idéntico.

En realidad, Hegel ha pretendido hacer una filosofía absoluta, que comprendiese todo, que encerrase todo, que explicase todo; y ha hecho un engendro que no explica nada. Pirotécnico, juglar, charlatán de buena sociedad, le dice Papini.

La filosofía de Schopenhauer es una galería de antiguos conocidos: en doctrina encontramos a Kant , a Buse, a Cristo, a los eleatas, a Platón, a los santos padres griegos y latinos... En el fondo hay dos cosas, voluntarismo y pesimismo. El voluntarismo, según Papini, lo escogió porque comprendió que ya no podía hacerse metafísica $\mathrm{nl}$ con principios físicos, ni con principios conceptuales; había que echar mano de la voluntad, de los instintos, del sentimiento. Pero la voluntad es entendida por Schopenhauer en forma equívoca y oscura, puesto que es fenómeno y es noumeno, algo incognoscible, como en Kant. La voluntad se comprende cuando es fenómeno, pero no cuando es noumeno. Así no se explica nada. 
El pensamiento es la consecuencia. - La vida es voluntad, la voluntad es esfuerzo, el esfuerzo es dolor, luego el dolor es la vida. Alles Leben ist Leiden. Todo vivir es sufrir.

Hay que aniquilar la necesidad, porque la necesidad crea el sufrimiento. Se puede vencer-el dolor de la vida y lograr su aniquilamiento por medio de la contemplación, por la música y por la piedad. Papini concluye diciendo que Schopenhauer amaba a Beethoven, pero más a Rosini, y que su obra maestra es como la de Rosini: una ópera buffa.

Augusto Comte considera que la nueva misión es la de mejorar a los hombres. No hay que dedicarse al servicio de un dios escondido, sino al de una divinidad visible, en la tierra y no en el paraíso. Comte es el Pontífice de esta nueva religión. Como la ciencia es aceptada por todos los hombres, es ella el medio de lograr este propósito. Para que pueda lograr este propósito es necesario que sea verdaderamente positiva y que sea completa. En este punto surge la ley de los tres estados y la jerarquía de las ciencias, con la creación de la sociología. Pero no basta la ciencia para tener unidos a los hombres. Comte crea entonces una Política Positiva, fundada sobre la institución de una casta de $\mathrm{sa}^{-}$ bios que quiere el bien de la humanidad. Pero como también el hambre necesita dogmas, símbolos y ceremonias, la filosofía positiva se convierte en religión positiva. Así se constituye la religión de la humanidad de la que Comtee es el Gran Sacerdote. Lee la imitación de Cristo, establece un templo en su casa y crea un culto a su amante muerta Isabel de vaux. Crea"el culto al Gran Ser, la Humanidad, nacido del Gran Fetiche: la Tierra, la cual forma parte del Gran Medio, el Espacio. La adoración a la Virgen se transforma en la de Clotilde, que es la forma más perfecta del Gran Ser, y la creencia en la vida futura, en el culto de los muertos, que viven eternamente en la forma, y que son registrados en el calendario positivista, y que son como los nuevos santos de la ciencia y de la humanidad. Hacer el proceso a Comte es como hacer el proceso al ochocientos y a Mr. Tout le Monde, dice Papini.

Spencer es un ingeniero ferroviario desocupado. Si no fuera por esta circunstancia, no hubiera escrito libros de filosofía. La teoría de la evolución estaba en boga. Su filósofo fué Spencer. Evolución es el paso de lo homogéneo a lo heterogéneo de lo indefinido a lo definido, de lo universal a lo particular. Disolución es lo contrario. Este es el gran descubrimiento de Spencer, dice Papini, irónicamente. Lo que no dice Spencer es cómo ocurre esta transi- 
ción. En suma: el conocimiento se forma por la adaptación del espíritu a las cosas. El apriori es hereditario, se forma por hábito. Considera que el egoismo es útil, porque es un estímulo a la acción. Es individualista y condena al Estado por lo mal que funciona con relación al individuo. El hombre es bueno, el mundo es óptimo, la natura es sabia. Estas tontas paradojas de Rousseau resuenan una vez más en esta moral para contemplativos y bellacos, dice Papini.

En cuanto a Nietzsche, se puede presentar una visión de conjunto de su filosofía, aunque no ha expuesto sino tres o cuatro ideas en diversas formas y diversos libros. Héla aquí:

Los cristianos y los pesimistas están equivocados; la vida tiene razón. No es verdad que la vida sea mala $y$, que haya que huir de ella o renegarla. Pero, para hacerla digna de ser vivida, hary que aceptarla como es; y no tratar de limitarla, de restringirla o de mejorarla. Hay que decir sí a la vida, pero a toda la vida. No es necesario rechazar nada, ni siquiera las malas pasoines o los instintos peligrosos. El instinto es el verdadero sabio. No se equivoca. Todo lo que hacemos por instinto es bueno. Alles Gute ist Instinkt. El hombre no peca jamás. Lo importante es no reprimir nuestras tendencias primordiales, y respetar el cuerpo, que es nuestro verdadero señor, en vez de ocuparnos del mejoramiento del alma o de la vida fantástica del espíritu. El cuerpo es sagrado y toda moral debe ser negada frente a sus exigencias (1). Los verdaderos sabios no son los moralistas, sino los hombres primitivos, los hombres del instinto, los muchachos, los sátiros, los salvajes, los bárbaros, y también, los que insurgen contra el arrebañamiento progresivo, los delincuentes. Debemos decir sí a la guerra, a la rapiña, al avasallamiento, a la agresión, y no a todas las morales, a las reglas, a los imperativos.

Esta es la liberación del hombre. Pero la liberación no es sino una primera etapa; la segunda es el advenimiento de la nueva raza, el super-hombre y el eterno retorno. En suma la filosofía de Nietzsche no es otra cosa que una transfiguración ditirámbica del naturalismo evolucionista.

En Nietzsche, la Vida hace el papel que en Schopenhauer hacía la Voluntad. Ella es todo y explica todo. Su exaltación es la finalidad del mundo. Ella ha dado origen al arte, a la ciencia, a la filosofía. Todas lás cosas son manifestaciones de la vida. Lo que la sirve es bueno; lo que le hace daño es malo. 
La crítica de Nietzsche no se refiere al contenido, sino al método. Le reprocha su imprecisión al definir conceptos fundamentales como Vida, Instinto, Potencia. La superficialidad con que ha tratado ciertos temas como el eterno retorno y sobre todo el cristianismo, al que considera equivocadamente doctrina de enfermos y débiles. Desde luego, no pasa inadvertida la simpatía que el gran detractor de todos los sistemas le profesa.

La primera edición de este libro, traía un capítulo final: Licenciamiento de la filosofía, que en posteriores ediciones fué suprimido. Su disentimiento de los sistemas filosóficos, lo llevó al pragmatismo, a un pragmatismo teórico y episódico que jamás puso en práctica.

Ahora quisiera detenerme un poco sobre Uomo Finito, sólo un momento. Francesco Flora, anti-papiniano, ha dicho en su historia de la Literatura Italiana, solamente estas palabras sobre Papini: Un Uomo Finito es todavía hoy el libro más significativo de Papini, como el que harmoniza sus cualidades y sus estros (pág. 589). Es poco decir, pero en cierto sentido es bastante. Son sus confesiones, la declaración apasionada de su terrible drama intelectual. Se confiesa pobre y feo, como Miguel Angel. Un bambino scontroso (receloso), un rospo. Una tía le dió el sobrenombre de Vecchio (viejo) cuando tenía seis o siete años. Solitario siempre, sin tomar parte en los juegos de los otros niños. El mismo lo dice: non ho avuto fancciulezza. Lo salvó de esta soledad sin luz la smania de saber. Y así empezó su vida de lector infatigable que lo hizo perder poco a poco la visfa. "Hombre del siglo pasado, se dejó tentar por la curiosidad intelectual ilimitada, que le proporcionaría un saber enciclopédico. Esta ambición, que es propia de la época - positivismo, cientificismo- lo condujo a hacer planes para escribir un diccionario, tarea en la que se frustraron sus mejores intentos. El Diccionario de un hombre salvaje, contiene algunos de sus trabajos de esta índole. Yo quisiera que muchos jóvenes de hoy leyeran algunas de estas páginas del Uomo Finito, el capítulo Miserfa, por ejemplo, para que vean si hay algo más emocionante, más humano, más terriblemente conmovedor que las confidencias de esta alma de niño enamorado de la sabiduría, del arte, en medio de todas las dificultades de su vida burguesa.

"Era feo y despreciable - lo sé y lo sabía también entonces- $-\mathrm{y}$ sin embargo bajo aquella fealdad y aquella miseria había un alma que quería saber, conocer la. verdad, embeberse de 
luz . . . había una mente que desde entonces miraba lo que los otros no ven y se nutría donde los demás no ven sino vacío y desolación. Por qué ninguno ha comprendido y me ha dado lo que me tocaba por derecho?"

Uomo Finito es un libro escéptico. El autor busca la grandeza y busca la verdad; pero no las encuentra. Así vuelve a sí mismo y se encuentra solo. Vuelve a su tierra toscana, no a la de "los florentinos bastardos, dulcetes y castrados que desde el seiscientos para acá han apostatádo y traicionado a su patria". Sus últimas palabras, dedicadas a la nueva generación, contienen interrogantes severas a los hombres nuevos. "No odio ni desprecio a los jóvenes. No los he rechazado. Los he tratado mal cuando he creído que fueran dignos de escuchar la verdad de un hombre. Los he esperado, los he deseado... para ver qué cosa podían hacer, qué tenían en el cuerpo. Los hubiera querido más violentos, más personales, más serios y menos fonógrafos. Pero no importa: así como son, los respeto y los estimo. Si hacen cosas mediocres o escriben tonterías, no los condeno". "No es esta una obra de arte; es una confesión a mí mismo y a los otros. Aquí aprenderéis a conocer al misántropo sentimental e injuriador que ha llegado a ser, si Dios quiere, antipático a tanta gente". En el parágrafo final del libro, dice a los jóvenes que si creen que de veras es un hombre acabado, deben al menos confesar que "soy acabado porque quise comenzaf demasiadas $\mathrm{co}^{-}$ sas y que no soy ya nada porque quise ser todo".

La conversión de Papini al catolicismo, marca la iniciación de una época de asombrosa fecundidad. Además, pocos escritores han logrado atraerse un mayor número de entusiastas lectores. La publicación de la vida de Cristo fué un verdadero gran suceso editorial. Fué traducido a todos los idiomas cultos de la tierra. El gran escritor florentino reproduce en el prefacio la inscripción que se colocó en una lastra de mármol, sobre la puerta principal del Palazzo Vecchio, entre el David de Miguel Angel y el Ercole de Baccio Bandinelli, que aludía a la elección de Cristo como Rey del pueblo Florentino, por decreto de la Signoría. El autor se siente orgulloso de reconocerse, aún hoy, después de cuatrocientos años de usurpaciones, súbdito y soldado de Cristo Rey. El libro, según la crítica de.Pangrazzi, no revela los secretos resortes de la conversión, lo cual hubiera sido muy interesante (3). De hecho, aparece aquí un nuevo Papini, el soldado de Cristo, el creyente iluminado por la verdad. La ordenada y poé- 
tica descripción de las diversas escenas de la vida de Cristo, nos hace pensar, según el mismo crítico, en el Giotto de Capella Scrovegni. El cuadro de Judas Iscariote, está entre los más interesantes, porque sugiere una reivindicación del traidor: la pequeña cantidad que recibió, la restitución de ella y el tremendo remordimiento... En realidad, el problema de Judas es uno de los mayores misterios de la religión. "Sólo dos seres en el mundo han sabido el secreto de Judas - dice Papini- Cristo y el traidor". Mucho se ha fantaseado sobre los motivos que indujeron a Judas a vender a Jesús. Pero nada esclarece definitivamente este misterio. Papini examina todas las posibilidades, aún las más distantes de las que admite la tradición, aún las más favorables a Judas. Todas resultan insuficientes y hasta contradictorias. Mayor es el desconcierto, si se toman en cuenta las palabras de Jesús al ver a Judas: "Amigo, le dice, a qué has venido", Amice, ad quid venistl? (Secundum Matthaeum, 26-50). Papini concluye que el misterio de Judas está ligado con doble nudo al misterio de la Redención.

En II Diavolo, continúa y aclara Papini este misterio, en el capítulo "El Beso de Judas". Comentando un escrito del poeta italiano Ferdinando Tirinnazzi, sostiene, de acuerdo con los evangelistas, que la noche de la cena, Satanás entró en Judas. El Judas que besa a Cristo es, por consiguiente Satanás que besa a Dios. En la tragedia de la Pasión hay, pues, un contacto corpóreo, y no solamente corpóreo, entreel Redentor y y el Adversario, dice Papini.

Tan importante como La vida de Cristo, y en cierto modo como su contra-polo y, si se quiere, como su complemento teológico, es II Diavolo (4). Lo que se ha propuesto Papini en este libro es estudiar, "guíado por un sentido de caridad y de misericordia", los siguientes problemas: 1) Las verdaderas causas de la rebelión de Lucifer; 2) las verdaderas relaciones entre Dios y el diablo; 3) las posibilidades de los hombres de hacer volver a Satanás a su primer estado, liberándonos en esta forma a todos de la tentación del mal.

Sobre el origen y naturaleza del diablo, Papini está de acuerdo con la vieja doctrina católica, que lo tiene como ángel caído, según las opiniones de Orígenes, Tertuliano, San Cipriano, San Ambrosio y otros, quienes lo han considerado como ente personal y no como disposición subjetiva del hombre al mal, como diablo interior. 
¿Por qué se rebsló Lucifer? Papini examina cada una de las causas que pueden haber dado origen a la rebelión: celos del hombre, criatura a la que el Padre iba a prodigar su afecto. $O$ tal vez, en su vanidad pensó que podía ser Cristo, es decir, imaginó que él era la criatura apropiada para realizar la encarnación del verbo. O cayó por impaciencia, como sugiere Dante en el canto XIX, 46-47, del Paraíso.

\section{il primo superbo}

che fu la somma d' ogai creatura, per non aspettar lune cadde acerbo.

O tal vez cayó por querer afirmar su libre voluntad, como anota San Anselmo de Canterbury? "Non solum autem voluit esse aequalis Deo, quia preaesumsit habere propiam voluntatem........."

Habría que pensar también si fué la soberbia, o sea la conjetura de ser igual a Dios lo que indujo a Luzbel a rebelarse contra su creador. Papini maneja textos bíblicos y recurre a autorizadas opiniones de teólogos; de todo lo cual deduce que la verdadera causa de la caída de Lucifer, no fué otro cosa que el odio, la envidia, los celos, la protervia. No podía ser la conquista de la libertad, ni el rechazo de la servidumbre (non serviam), puesto que el diablo fué creado libre. Por eso justamente pudo elegir, y eligió el odío.

La segunda cuestión, e sean las relaciones entre Dios y e! Diablo, está tratada por Papini con fruición, y con un aire de revelar hechos en los que casi nadie toma interés.

El capítulo V. pone de manifiesto las relaciones entre Lucifer y Dios, tomando como base algunos textos del Antiguo Testamento, los escritos de algunos santos, entre ellos San Gregorio Magno. "Nuestro Señor - dice este santo papa- venido para la redención del género humano, se volvió él mismo en cierto modo anzuelo, para matar al Diablo. Tomó un cuerpo para inducir a este Behemoth (el Demonio) a matar la carne que se volvió así para' él un cebo. Deseando injustamente la muerte del cuerpo de Cristo, nos perdió a nosotros que legítimamente le pertenecíamos. Esta referencia concuerda con la alusión en otro parágrafo al libro de Job, en el que, como es sabido, el diablo se presenta ante el Señor en medio de una legión de ángeles, y el Señor lo acoge y conversa con él tranquilamente, y hasta le pide informes sobre lo que ha visto en la tierra y especialmente sobre 
su siervo Job: (Et dixit Dominus at Saten: Nunquid considerast! servum meun Job, quod non sit si similis in terra, vir simplex et rectus, ac timens Deum, et recadens a malo, et adhue retinens innocentiam? (Job 2-2).

Hondamente conmovedoras son las páginas escritas sobre las tentaciones de Jesús en el capítulo VI y sobre el significado de su rechazo. Hace resaltar Papini el sentido materialista de las tres tentaciones, y sugiere que Cristo realizó los tres milagros en forma espiritual; el primero, el del pan, en el sacramento de la Eucaristía; el segundo, en vez de precipitarse en vuelo, voló hacid lo alto en la Ascensión; a la tercera tentación, que es la oferta de todos los reinos de la tierra, responde Jesús a Pilatos: "mi reino no es de este mundo".

En el capítulo VII, consigna Papini las relaciones entre el Diablo y los siervos de Dios. El Diablo y Miguel Arcángel, quien no osa pronunciar contra Satanás ningún juicio injurioso, limitándose a decirle, en su disputa por el cuerpo de Moisés: "el Señor te castigue"; así com o"Satanás y Moisés", quien ha sido representado por Buonarroti con el mismo símbolo que el principio de las tinieblas, los cuernos, destacan aspectos de la relación de los siervos de Dios con Lucifer. Sobre todo es interesante esta no muy conocida aproximación entre el Profeta, que a veces tuvo violencias terribles y que fue dotado de una potencia verdaderamente mágica, como se leeten ese libro maravilloso que se llama El Exodo, y que muy bien podría ser aprovechado hoy por el cinematógrafo.

La relación entre el Diablo y los hombres, da ocasión a Papini para disertar sobre Adán y Eva. Como curiosidad literaria, hace mención a la tragedia escrita en latín por Hugo Grozio, a menos de dieciocho años de edad, en 1061, Adamus exul, uno de los mayores genios holandeses, el mismo que conocemos como gran internacionalista, autor de la-famosa obra De Jure Belli et Pacis. Esta obra posiblemente inspiró a Milton El Paraíso Perdido. Lo singular en ella es que Satanás se dirige a Adán antes que a Eva, para persuadirlo de que desobedezca, siendo rechazado rotundamente. Furibundo, al verse repudiado, Satanás anuncia al hombre su venganza y su odio perpetuo. Entonces es cuando pone en acción todo el caudal de su astucia y de su perversidad: se gana a la mujer.

El tercer problema con relación al Diablio es el más escabroso: la posibilidad de los hombres de hacer volver a Satanás 
a su primer estado, liberándonos en esta forma a todos de la tentación del mal. En el fondo, el problema que plantea traduce la tendencia de su noble naturaleza. Papini es un idealista; y como todos los idealistas, anhela cancelar los vestigios del mal sobre la tierra. Sueña en la posibilidad de un cristianismo auténtico, que elimine la envidia, el lucro, la mentira, el odio, la agresividad, la codicia. Acaso su temperamento entusiasta, su furia ética, no le permitló reflexionar sobre aquel versículo del Eclesiastés, que dice:

\section{perversi difficile corriguntur (1-15)}

Pero el caso es que, si fuera posible la elevación y significación de la naturaleza humana, conforme a los preceptos del cristianismo, si fuera posible alcanzar la perfección, a imitación del Padre, si los hombres renunciaran a la maldad, al vicio, a la prepotencia y a la codicia de bienes materiales; se plantearía en seguida el problema de la desocupación del Diablo. Si los hombres se volvieran santos, ¿se volvería santo también el Adversario? y en estas condiciones, ¿sería perdonado por Dios? He aquí el intrincado problema teológico que presenta Papini. En otros términos, el trágico dualismo ético que desgarra las entrañas del universo, ¿tendría alguna vez solución? ¿Lo que fué excluído del ser volvería alguna yez al seno deleser, produciéndose en esta forma el acuerdo final la definitiva armonía del todo y por lo tanto la universal beatitud? Al menos Orígenes lo creía así, - apunta Papini. Creía que la Redención era el comienzo del retorno de todos los seres creados, ahora divididos y corrompidos, al seno de la perfección divina. Además la Redención no afectaba sólo a los hombres, sino a todas las cosas. Con un sentido evidentemente neo-platónico-, Orígenes sostenía que la Creación era la expiración de Dios, mientras que la Encarnación era el comienzo de la aspiración, del retorno de todos los seres de abajo hacia arriba, del mal al bien, de la materia al espíritu, de lo transitorio y temporal a lo eterno, la apocatástasis. Se advierte pues el alcance metafísico del problema planteado, y la dificultad de encontrar una solución con los reducidos medios de que dispone el hombre. Acaso una de las más acusadas características de la existencia es el interrogar ansiosamente, sabiendo que es inútil el afán y que es impenetrable el silencio. Sólo la vía de la fe religiosa ofrece soluciones, pues la inteligencia, 
habituada al análisis riguroso y a la aplicación de la lógica, no alcanza a descifrar los enigmas últimos.

Para completar esta breve visión de la figura intelectual de Papini, debo mencionar sus libros Dante Vivo, San Agustín y Miguel Angel. No es mi intención referirme detenidamente a cada uno de estos. Basta decir que al escribirlos, Papini ha tenido en cuenta tres valores: la humanidad, la grandeza y la intimidad cordial. Ha considerado tres de los más excelsos ejemplares humanos, como si hubiera querido presentar estas vidas como paradigmas de la estirpe. Las ha bosquejado en su majestuosa grandeza, en la realización de los mayores designios de santidad, de poesía, y de creación artística. Es ostensible la simpatía que emana de estas figuras trazadas magistralmente, con sentido de la realidad, del ambiente en que vivieron, como ya lo había hecho hasta cierto punto, al exponer las doctrinas de los filósofos en su "Crepúsculo"; pero en vez de la ironía y el afán demoledor que puso para destruir los sistemas de filosofía, pone en estas vidas comprensión, emocion, ternura, amor en una palabra. Se identifica con los personajes, los hace vivir una vida, los actualiza, los presenta en sus aspectos más humildes, en su empeño por vencer las dificultades que se les presentan, y venciéndolas por fin en virtud de la soberana decisión de su voluntad y gracias al poder de su genio. Dante vivo es sin duda la mejor biografía del poeta.l Lo que Sócrates hizo con la filosofía, hace él con Dante; lo traee del Cielo a la tierrars San Agustín nos seduce por el relato de su vida juvenil, proclive a tropezar en obstáculos que para otros hubieran sido insalvables. Y Miguel Angel muestra su terribilidad, pero al mismo tiempo deja al descubierto los aspectos sensibles y delicados de su personalidad. Pese a la objetividad, garantizada por la documentación, en cada una de estas vidas egregias se deja entrever al autor, cual si las hubiera escogido como posibles modalidades de la grandeza a la que siempre aspiró.

Así, en la figura intelectual, o más bien noología de Papini encontramos estas tres dimensiones: la divina, la diabólica y la humana. En el fondo, nada interesa a Papini tanto como la existencia y los problemas del hombre. En este sentido, podría adscribírsele, con reservas, a la llamada corriente existencialista, sobre todo si se tiene en cuenta su repudio a la filosofía racionalista y su resuelta adhesión a la fe. Sin el barroquismo de Unámuno, pero tan inquieto y contradictorio como él, afirma los mis- 
mos principios y se mueve en la misma órbita de ideas; con la diferencia de que el pensador español, más nutrido por la levadura filosófica y más empeñado en demostrar lo indemostrable, hace esfuerzos de ahondamiento, para concluir casi siempre en soluciones verbales y metafóricas a los problemas metafísicos y teológicos; en tanto que Papini, pasando con premura sobre las anfractuosidades de la dialéctica, enarbola los resultados, las soluciones, las banderas victoriosas. El terrible escritor florentino se ahorra el trámite, y pasa de frente a la polémica, a la lucha abierta y sin cuartel. Las cartas a los hombres del Papa Celestino VI son cordiales pero duras advertencias a los hombres, llenas de reproches, contra quienes en vez de cumplir los preceptos de Cristo, han convertido la vida y la cultura en pasto inhumano y despreciables de los sentidos y de los más bajos instintos. Una especie de llamada al orden, a la vez que un requerimiento afectuoso del pastor ideal para que los hombres vuelvan a la senda del bien.

Papini es católico, pero no es un místico ni un contemplador de las supremas verdades. Temperamento robusto y batallador, está en guerra constante, en furiosa guerra contra sofistas, filisteos y fariseos. No da tregua a la espada. A la vez que escribe libros en los que vuelca su simpatía o su admiración, -y que desde luego son también polémicos - esgrime la más severa crítica en ediciones que pueden llamarse Gog o el Libro Negro, en las que analizásing piedaailos ldiversos aspectos de la cultura contemporánea: ideas, libros, autores, opiniones. Como si en los repliegues profundos de su espíritu, el agresivo escritor estuviera convencido, como el solitario filósofo de Efeso, que Polemos panton men pater esti. Algo puede significar como corroboración de su inclinación beligerante, su admiración por el más bello libro de Nietzsche. Así hablaba Zarathustra, Il piú bel poema in lingus tedesca che sía stato scrito dopo il Faust. (Crep. de los Fil.) Pero esta impresión se desvanece si se advierte que, bajo el estruendo de la violencia, de esa mordacidad sin paralelo en la que Croce resulta "padreterno de la filosofía y senatore per censo" (5), D'Anunzio "gelatiere abruzzise" y Sartre "el responsable y beneficiario de la más siniestra impostura literaria de esta post-guerra de sapos histéricos", si se advierte, digo, su profundo amor a la verdad, al verdadero arte, a la verdadera filosofía, a la verdadera vida cristiana; al arte que no se complace en la frivolidad o en la exaltación de las más bajas y vergonzosas 
pasiones, al arte que va más lejos que las palabras vacías y las frases sin sentido, al arte de los grandes artistas, al que trae algún mensaje trascendente para el hombre. Si se considera, además, lo que ha hecho para despertar el sentido de la vida cristiana, abordando los problemas teológicos y éticos en el campo de la alta cultura, a la vez que suscitaba la curiosidad del gran públi$\mathrm{co}$, se tiene que admitir que bajo la máscara a veces agria, a veces irónica, y casi siempre agresiva, hay otro Papini: el del amor, el de la ternura, el de la compasión cristiana, el que tal vez presumiendo de reformador, ha sentido la angustia que debió conmover a Savonarola, al célebre monje herético súbdito de Cristo, Rey de Florencia. ¿Tienen acaso otro sentido las candentes y apocalípticas palabra del Papa Celestino VII? ¿No ha de venir el diluvio de fuego del Espíritu Santo, después del diluvio de agua deT Padre y el diluvio de sangre del Hijo? Hijos míos, hermanos míos -dice al imaginario papa, dirigiéndose al pueblo que se llama cristiano- no puedo callar por más tiempo. He esperado demasiado. El infinito dolor del mundo se agruma y fermenta en mi alma de padre, quiero que mi voz sea su voz. Si no habla quien representa a Cristo en la tierra, ¿quién, pues, hablará?

\section{La polémica sobre Âmérica Latina.}

\section{Biblioteca de Letras}

El eximio polémistă no podía olvidar la América, a la América Latina, que "es la que más urge a un italiano". Como es natural, Papini "se siente más cerca de los hijos de la civilización mediterránea". Al menos insinúa en esta forma una justificación sentimental de su derecho a enjuiciar con severidad la obra de América. Veamos sucintamente el fatal inventario.

América ha recibido todo de Europa: población, religión, literatura, arte, ciencia, filosofía.

Se pregunta, no sin cierta razón, ¿qué ha hecho América con estos tesoros? ¿"En qué medida ha llevado su contribución a la civilización universal"?

El recuento es desolador: "ningún teólogo, ningún místico famoso, pero ni siquiera un movimiento herético". "En todo el continente un solo santo: Santa Rosa de Lima que, por otra parte, no alcanza la grandeza ni la celebridad de una Catalina de Siena, de una Teresa de Avila". 
En filosofía, "ni filósofos originales ni sistemas propios". En literatura, "las cosas van mejor". Algunos escritores de América "han logrado pasar al Atlóntico y ser traducidos a lenguas europeas". "El único escritor nacido en América que alcanzó una posición de importancia en las letras españolas, fue el Inca Garcilaso de la Vega. Pero ni este mismo alcanza en la historia de las letras españolas el puesto de su homónimo el poeta Garcilaso de la Vega".

En arte, dice Papini, las cosas van peor. "Ningún artista me parece que ofrezca una creación verdaderamente suya, independiente de las formas y de las escuelas europeas". "Uno solo, el mexicano Diego Rivera, ha llegado a imponer su nombre a la consideración de los críticos europeos, pero no ha conquistado ni la fama ni ha ejercido la influencia, por ejemplo, de un Pablo Picasso".

¿Cuáles pueden ser las causas - se pregunta- de la ausencia de figuras americanas de primer plano en el cuadro de la civilización mundial? ¿Ignorancia de los europeos? ¿Acaso existen genios en América que no son conocidos por los europeos? Si hubiera habido en América un solo genio de primera magnitud, todos, en Europa, lo hubiéramos sabido, dice el polemista.

Otra causa a la que podría atribuirse la esterilidad cultural de América sería la escasez de población americana con respecto a la europea. "Perolen Europa hay pequeños países que han dado su contribución a la cultura universal. Ejemplo, Holanda, que dió a Erasmó, a Rembrandt, a Huygens.

Otra razón sería, en concepto de Papini, la lentitud con la que se ha formado una verdadera y propia raza nueva, por el cruzamiento entre los indígenas y los europeos inmigrantes. Una vez lograda la fusión de los elementos diversos a través del siglo XIX, debió afirmarse una cultura autónoma.

Por último, alude Papini a la dificultad de las comunicaciones. Es cierto que todas estas razones tienen su parte en el retardo del proceso cultural de América. "Se trata de países vastísimos, en parte inexplorados, donde no es fácil la circulación de las ideas y la alta tensión del espíritu".

Pero, la causa más importante de nuestra situación espiritual, de nuestra inferior posición cultural frente a Europa, es otra. Trascribo literalmente las palabras de Papini: "Temo que la cau- 
sa más importante sea otra. La energía espiritual de un pueblo es en realidad relativamente fija: si es usada en un cierto orden de actividad, no puede manifestarse en otros órdenes. La América latina hasta ahora ha gastado la mayor parte del capital de su inteligencia en la lucha por el aprovechamiento de su suelo y en la pelea política. Poca fuerza le queda para las actividades superiores del espíritu".

La reacción de los intelectuales de América tenía que producirse. En diversas publicaciones exteriorizaron su disgusto (6). Fernando Diez de Medina admitiendo de mala gana las afirmaciones de Papini, sostuvo que en América está naciendo la conciencia moral de una nueva humanidad". Es verdad, pero también lo es que no sólo en América está naciendo esa conciencia, sino en Europa misma; y también en Ásia. Se está formando en todo el mundo una conciencia de la humanidad, sin limitaciones ni prejuicios. La creación de numerosos organismos internacionales revela que se está superando el nacionalismo tradicional, que creía en la posibilidad de realizar todos los valores humanos dentro de determinadas fronteras geográficas. El prejuicio de razas superiores ha sufrido también un rudo golpe a consecuencia de la última conflagración mundial, y la liberación del hombre de la servidumbre es hoy un ideal universal. Los nombres de Bolívar, Sucre, San Martín, Artigas, que cita Fernando Diez de Medina, como genios de Ámérica, hacen pensar justamente que los problemas políticos y en generalilos de orden, práctico, inclusive los económicos, absorven en gran parte las energías de nuestros pueblos.

Mariano Picón Salas, el destacado ensayista venezolano, intervino en la polémica determinando el terreno con más precisión. "No por lo que América ha sido, sino por lo que América quiere ser, es como debe juzgársenos". Sus palabras, son una apelación a la tolerancia. En realidad, América está empezando a vivir. Lo vivido, la colonia, fué, como dice Picón Salas, "una expresión ultramarina del imperio español". No pudo ser más; no podía serlo, dentro del sistema español de sujección intelectual y aprovechamiento material de las colonias. Después, en el siglo XIX, la independencia política y las rencillas entre los soldados libertadores, junto con nuestro incipiente desarrollo económico y cultural, no podían crear un clima propicio a la formación de una floreciente cultura nueva. Además, el europeo, en función de la cultura, como en otras cosas, está muy distante de 
nosotros. Nuestra tarea, pues, es muy diversa de la europea. Nuestro punto de partida, nuestros problemas, nuestra población, nuestros ideales, son en cierto modo diferentes de los problemas de Europa. Comparar a América con Europa no puede producir otro resultado que desalentarnos, por la tremenda desproporción, por la ventaja de tiempo y de calidad que nos lleva Europa. Además, como dice el mismo Picón Salas, "cultura americana no es tan sólo la de las élites". En Europa, en líneas generales, el problema de la cultura puede reducirse al de las élites, porque se supone que los demás problemas, los básicos, están resueltos. En. América nos encontramos en una situación muy diferente: "debemos incorporar a la vida y técnicas modernas a las masas indígenas". Aparte la población en estado semi-civilizado o no civilizado de las inmensas selvas americanas, existe el grave problema de atraer hacia la vida moderna extensos núcleos de población, que viven vegetativamente, en estado de aislamiento cultural a través de los siglos, dominados por una economía primitiva y víctimas del desamparo o de la indiferencia de los centros de civilización activa y moderna, cuando no sufren la explotación inmisericorde a que los condena un régimen de feudalismo extorsionador y anacrónico. En una palabra, América no ha asimilado aún perfectamente los contenidos y formas de la cultura europea que nos trajeron los conquistadores y que después han seguido importando las élites, generalmente en sus aspectos exteriores, sinn que cmucha decese hayan echado raíces en la tierra adaptándose al nuevo medio geográfico y a las nuevas condiciones antropológicas. En este sentido, se debe tener presente que - como dice el mismo Picón Salas- "América latina es mucho menos latina de lo que sospecha el escritor florentino" y hasta podría decirse de lo que sospecha la mayoría de los europeos que no nos conocen. En realidad, América es un complejo sociológico indo-latino. El principal aporte latino es el de la religión católica y los idiomas neo-latinos. Fuera de estos elementos, no puede decirse que se cultiva ni se promueve la tradición latina o greco-latina, con excepción de algunos centros académicos aislados. La gloriosa tradición greco-latina, que cultivaron y cultivan las universidades de Europa y que contribuyó a formar las más esclarecidas mentalidades de la cultura occidental, ha sido entre nosotros casi completamente abandonada. La educación misma se orienta por los cauces de la utilidad, influída por los ejemplos anglo-sajones, apartándose cada vez más 
de las fuentes originales de la cultura europea. Así, en vez de tratar de integrarnos en un movimiento natural hacia las vertientes de la latinidad, y desde luego hacia las más próximas vertientes indígenas de nuestro preclaro origen americáno, nuestro interés, por razones económicas converge hacia un panamericanismo de índole política y epidérmica, en la que América latina espera encontrar su bienestar, con mengua de su personalidad y de su emoción hondamente indígena y latina.

Baldomero Sanín Cano, no podía dejar de acudir a esta cita de la inteligencia y de la dignidad americanas. El viejo y prestigioso escritor no niega que América haya recibido de Europa un bagaje de cultura. ¿Pero cuál es? La civilización española de la época del descubrimiento, dice, era una civilización pōbre. España a quién le tocó la suerte del descubrimiento acababa de salir de una guerra de siete siglos. Es cierto. España no se encontraba entonces, en una situación floreciente. La guerra contra los moros debió debilitar sus energías culturales, aunque no redujera su espíritu guerrero, acrecentado por la misma guerra. Por otra parte, la economía del pueblo español, cuando la agricultura fué casi abandonada por la expulsión de los árabes, no podía alentar grandes expectativas. En estas condiciones vinieron los españoles a América. A la aseveración de Papini, de que los españoles trajeron a América su civilización y su cultura, responde Sanín Cano: "Se trasladaron ellos y trajeron la lengua, la cruz y los toros, cuya traslación ho implica desmedido esfuerzo. América, mal que bien, -continúa- conserva esas tres dádivas, y por lo que háce a la lengua y a la religión, algunos países, Colombia entre ellos, las cultivaron con esmero y laudable entendimiento". Los peruanos podríamos decir lo mismo. Nosotros hemos conservado también las tres dádivas. Pero seríamos mezquinos si no reconociéramos la obra de España en escala bastante más amplia. La bellísima arquitectura de algunas ciudades nuestras, en primer lugar el Cuzco, es española. En pintura, en música, en derecho, en costumbres, no es difícil advertir el sello de la cultura española. La incorporación de nuestra selva a la civilización hasta los días que corren está en manos de congregaciones religiosas españolas. Sin embargo, no se le puede exigir a América - que no es Europa-que se convierta en otra Europa. Además, quienes vinieron de Europa no fueron los sabios, sino los soldados, los aventureros. La cultura 
europea no vino a América traída por hombres cultos, sino precisamente por incultos. Además de estas importantes limitaciones, los conquistadores no favorecieron las culturas autóctonas; sino al contrario, las combatieron y "las extirparon cuidadosamente, como apunta Sanin Cano, por ser contrarias a la religión cristiana y no reconocer la soberanía de la corona española".

Otro de los polemistas importantes fue el chileno Vicente Huidobro. Su exaltada sensibilidad de poeta no le permitió mantener frente a Papini la mesura intelectual que hubiera sido necesaria. Estalló en un impulso revanchista: El mundo no le debe nada a Italia, dijo; como los jugadores, cuando dicen "siasmo pari", estamos a manos. Pero en seguida dijo también que favorecía la inmigración italiana, con lo cual reconoció la deuda que les tenemos los americanos a los inmigrantes italianos como factor formativo de nuestra independencia y estructuración demótica y económica modernas.

Aparte las razones geográficas, tales como la excesiva extensión del territorio, la dificultad de comunicaciones, la escasez de población y tal vez el encontrarse precisamente en formación esa "raza nueva", no es absurdo pensar que gran parte de las energías de los americanos se gastan en el aprovechamiento del suelo, con poca ventaja, porque son las grandes empresas capitalistas las que sejllevan ab extranjero los mayores dividendos. La otra parte importante de las energías intelectuales de los americanos se las lleva la política. "América es el "continente de las dictaduras y las revoluciones. Los períodos de paz constitucional son a menudo transitorios. Lo permanente es la guerra civil, la proscripción de partidos políticos, el exilio en masa de los adversarios. En esta lucha sin tregua, que traduce la falta de madurez política de nuestros pueblos, se dilapida la energía que podría dedicarse a la creación de obras de cultura. Los intelectuales no viven en Europa ni en ninguna parte del mundo en condición de privilegiados. Bien se sabe que "Littere non dant panem sed aliquando famem". Pero en América la vida intelectual es doblemente difícil, por la falta de amplios sectores de cultura popular capaces de absorver la producción intelectual. La escasez de lectores hace del escritor americano un héroe 0 un obstinado. Pueblos con subidos índices de analfabetismo y ambientes semi-cultivados, desprovistos de curiosidad cultural desinteresada, no permiten avanzar mucho más allá de la actividad 
solitaria. Posiblemente, la meritoria labor de las editoriales modernas y la que realizan las instituciones culturales privadas tendrá con el tiempo resultados favorables para la elevación del nivel espiritual de nuestras poblaciones.

Sin embargo, Papini afirma que no es pesimista. Tiene fe "en la potencia intelectual de América". Sus palabras no son una "reprobación", sino "un llamamiento fraternal de esperan$z a "$ ". "Están inspiradas en el amor a la eterna civilización latina". Pues bien, si esa potencia es efectiva, si la capacidad intelectual de los americanos debe emplearse con eficacia, no cabe sino señalar dos rutas: la asimilación de la cultura europeooccidental y el ahondamiento de nuestras propias raíces indígenas. Asimilación es justamente lo opuesto a imitación. Implica digerir, o sea separar y seleccionar; y luego convertir lo seleccionado en carne y substancia nuestra. Como simios o papagallos de Europa, (7) nunca alcanzaremos nivel de decoro ni de respeto. Desde luego, asimilación supone personalidad, conciencia de nuestra posición, de nuestra individualidad, de nuestro destino, de nuestro ser. De colonia política y mental, debemos pasar a la categoría superior de pueblos independientes, con criterio propio y con intereses y designios propios también. Para lograr este tipo de conciencia, que es la raíz y el fundamento de nuestro ser americano, estamos obligados a permanecer leales a nuestro glorioso pasado, a nuestra historia, a nuestros problemas. Que nos venga de fuera la técnica, incluso las modas y las escuelas; pero el acento, la emoción no pueden dejar de ser indígenas. Escuchar la voz de nuestro pasado, es ahondar en nuestra raíz intransferible, es adquirir conciencia de lo que realmente somos. Y, además, es ofrecer al mundo lo que el mundo espera de nosotros. El severo juicio de Papini, es la expresión de lo que el mundo le exige a América. En buena cuenta, la devolución del préstamo. Europa, especialmente, no puede dejar de creer que América es la tierra de la esperanza ;en la que una nueva humanidad, libre de los prejuicios añejos, de las rivalidades tradicionales que cada década estallan en una cruenta conflagración mundial, establezca definitivamente un reino de justicia y de prosperidad, un reino de fraternidad para todos los hombres. El imperio de los prejuicios europeos consignados en el libro de Antonello Gerbi: La Disputa del Nuevo Mundo - debilidad de la naturaleza americana, de las especies animales, la hostilidad del medio, así como la inferioridad en cuerpo y espíritu del hombre americano, - ha sido 
felizmente superado. Las deficiencias de América son ciertas y evidentes; pero con todo, Europa no puede negar la cuantiosa contribución americana, como realidad y como posibilidad, a su desarrollo económico y cultural. De allí el interés cada vez más creciente en Europa por América y la intensificación de rəlaciones de todo orden entre ambos continentes. Desgraciadamente, no todo lo que se puede hacer se ha hecho. Pero se puede esperar que estos contactos se intensifiquen en beneficio recíproco.

A Papini, compatriota de Américo Vespucio, le debemos los americanos este balance, por el momento desfavorable, pero muy útil para aprender a examinar con precisión y objetividad los problemas fundamentales de nuestra cultura. Mejor que el halago cortesano es el juicio riguroso, como estímulo para el perfeccionamiento de la obra. Estando en Padua - cuenta Vasari- para ciertos trabajos suyos, Donatello, y siendo tenido por todos allí como milagroso, "si deliberó di voler tornare a Fiorenza, dicendo che, se piú vi fosse, tutto quello che sapeva dimenticato si avrebbe, essendovi tanto laudato da agmuno, e che volentieri nella sua patria tornava per essere poi colá di continuo biasimato, il quale biasimo gli dava cagione di studio e conseguentemente di glorla maggiore". Sigamos los americanos el ejemplo de Donatello. En vez de sentirnos ofendidos, examinemos si hay verdad en los juicios adversos y pensemos que, por lo menos, América tiene hoy críticos, pero no tiene los detractores de otras épocas. El "biasimo", dacensura, los reproches que nos hagan, nos darán causa de estudio y de mayor gloria.

Leal a sus convicciones, leal a sus conciudadanos, a Italia, a su pequeña patria Florencia, a todos los hombres sus hermanos, al ser absoluto y desde luego a su propio ser; leal a la verdad, a la belleza, a la grandeza, su obstinada y fervorosa lealtad lo volvió soldado de sus principios, y por ellos vivió y lucho, paralítico y casi ciego, en los últimos tiempos.

Quizás por ello mismo, por haber perdido la visión física, se agudizó en él la sensibilidad interior, la del espíritu, la que contempla de antemano la dicha verdadera y la certeza definitiva. Como los grandes creadores de la Florencia renacentista, ha dejado una obra perdurable. Hubiera podido decir como el Poeta: non omnis moriar, multaque para mei vitabit Libitinam". No morirá, ciertamente, porque nos ha legado un tesoro inagotable de 
bəlleza, de meditación, de señorío y de generosidad. Emilio Cecchi, en reciente homenaje al amigo desaparecido, ha dicho que "él era y fué siempre el más listo a compartir con los demás el pan de la cultura y de la poesía; a participar sus descubrimientos de lector insaciable y a promover útiles y dignas divulgaciones". Y Tomasso Gallarati-Scotti, que lo conoció íntimamente, en palabras que traducen los más delicados sentimientos, lo defiende de la acusación de cínico, y afirma "la sinceridad de su muerte", "la preparación lenta, meditada, conscientemente aceptada, en conformidad con los dolores de la Cruz". Así, con gestos y sonidos que sólo una persona muy amada - su nieta Ana- podía interpretar, sin literatura y sin el menor propósito de despertar la admiración del mundo, pronunció las últimas palabras de poesía, "porque poesín era su vocación".

\section{NOTAS}

(1) "Hinter deinen Gedanken und Gefühlen, mein Brüder, steht ein nüchtiger Gebieter, ein unbekannter Weiser- der heisst Selbst. In deinen Leib wohnt er, dein Leib ist er" (JV. 47) cit. Papini.

(2) Cfr. Cerpuscolo dei Filosofi, pág. 159.

(3) En un bellísimo artículo, Corriere dela Sera, 8 de agosto de 1956, Tomaso Gallarati Scotti da a conocer un par de cartas escritas por Papini al Sacerdote Cesare Angelini, è Ias que se pueden encontrar preciosos datos sobre su conversión. Una de ellas, fechada en Santa Marinella, Roma, el 16 de mayo de 1918, dice: "Carissimo Angelini, ho aspettato fino ad oggi colla speranza di poterle scrivire una letterona lunga con tutte le cose che da tanto tempo mi stanno in cuore e destinate a lei. Ma non ci riesco neppure oggi. Questa é una semplice staffetta per dirle che le voglio bene a che prima di partire da qui le scriveró una lettera como si deve, per parlarle della mia lenta, ma profonda mutazione spirituale. Sono sempre stato, nel fondo, contro le apparenze, un mistico, ma ora sto diventando e non soltanto per teoria, un cristiano. $\mathrm{E}$ anche $\mathrm{i}$ fatti di questi anni mi hanno riportato alla grande scoperta che é nel Vangelo, l'unica, che tutti conoscono e qussi nessuno applica e vive".

La otra carta está fechada en Pieve Santo Stefano (Arezzo), el 20 de julio de 1918. Es solo, un fragmento: "Stto facendo fra me e me la teoria dell"amore........... ma dell'amore como fu comandato da Jesu, E a Gesú mi sono avvicinato con nuovo spirito, e credo di averlo sentito como pochi, oggi, lo sentono, anche tra quelli che si dan l'aria di mistici. E ho scoperto che Gesú é sempre solo, como sole e stato fin da 
principio, e che pure non c'é salvezza al fuori di lui; non nel senso tra dizionale, teologico. Lei forse $\mathrm{mi}$ intende".

El estado de ánimo que se refleja en estas cartas, explica la Storia di Cristo, si bien es cierto que fuera de estos documentos personales, Papini no hizo literatura con sus sentimientos religiosos, tal vez por el pudor que se opone a la exhibición directa de la intimidad.

(4) Cuando apareció el libro, Armando Carlini dijo en Idea, una de las más prestigiosas tribunas intelectuales de Italia: $\mathrm{La}$ tesis de $\mathrm{Pa}$ pini en el hecho es verdadera : es un sentido cristiano, más cristiano y sólo aparentemente contradictorio con el escepticismo que parece dominante en el mundo moderno. Quien piensa en las prolongadas contingencias de este hombre, que desde hace medio siglo tiene empeñada tan grande parte de nuestra literatura, y en su incesante debatir en público el problema del cual él mismo tal vez se ha hecho consciente, sólo con lentitud, porque lo dominaba demasiado el amor de la bella forma y el deseo de ser original - quien. piensa, digo, en su historia, no puede querer discutir hasta qué punto la tesis del volumen sea compatible con la doctrina consagrada por el magisterio soberano de la Iglesia, a la que Papini, buen católico, no quisiera, ciertamente, contradecir. Tomemos, pues, este volumen como expresión del sentimiento noble y generoso del hombre y del poeta fantasioso. Hoy el Cristianismo, para expandirse en el mundo contemporáneo, tiene necesidad sobre todo de una palabra de fé, como en los primeros tiempos, cuando encendió los corazones y transformó la vida social entera.

En Letture, los RR. PP. Jesuitas se explicaron así : Cómo ha podido Papini, tan agudo conocedor del pensamiento cristiano y su infatigable propugnador por un trentenio, desatar este ataque contra la eternidad de las penas infernales, dogma característico y fundamental de la Iglesia católica? Quien tiene familiaridad con el arteodesmelenado de $\mathrm{Pa}-$ pini, sabe qứe él no retrocede siquiera ante los estratagemas más extravagantes. Tira la piedra contra una bella vitrina que a nadie llamaba la atención. Si hubiese afirmado la eternidad de las penas todos habrían hablado de melancolía, de próximo candidato a la tumba. Fingiendo negarla, reclama la atención general sobre la verdad más terrorífica, frente a la cual la humanidad pasa con feliz indiferencia. Santo Tomás teje un diálogo consigo mismo para poner en relieve el pro y el contra de una verdad. Papini teje el diálogo con los demás. Lanza el "Videtur quod non........" seguro de que los otros gritarán fuertemente el "sed contra".

Mario Stefanile, en Il Mattino, dijo: Tentado......... Papini......... por el Diablo? Sí, pero no en el plano estéril del odio, sino en el plano positivo y activo del amor.

(5) En Conversazioni Critiche, serie IV, 1951, Croce le dedica a Papini en cordial correspondencia un extenso parágrafo, del cual entresacamos: "a su vena de escritor no responden ni la fuerza de la mente, ni la abundancia del serio, recogido, tenaz y verecundo sentir. Por eso no puede, como crítico, ir más allá de alguna observación apropiada; ni en cuanto al sentimiento, ir más allá de alguna fugaz expresión de 
afecto, de alguna fresca impresión de hombres y cosas. Si hubiese sabido educarse y vigilarse severamente, habría escrito no muchas páginas, sino buenas y tal vez mejores que aquellas pocas que las personas de gusto pueden encontrar en sus demasiados volúmenes, $y$, con alguna reserva, alabar, practicando hacia él aquella justicia que él no observa hacia los demás. Pero, desgraciadamente, en él hay un prepotente invencible, connaturado - que no lo abandona jamás, ni joven, ni viejo, ni hombre del desórden, ni hombre del orden, ni blasfemador, ni piadoso, ni ateo ni católico, - el demonio del exhibicionismo, del ceretanismo, de la miserable vanidad que quiere suscitar en torno a sí maravilla o escándalo, sorprendiendo y engañando la imaginación de la gente". La reacción de Croce se explica mejor si se lee la tremenda diatriba filosófica que escribió Papini contra el ilustre filósofo y escritor, en el volumen "Stroncature". No por agravios superficiales o personales escribe un eminente intelectual en tono tan apasionado y dejando ver a las claras que log ataques del crítico lo habian herido en lo más vivo. Es la vanidad intelectual la que responde, la vanidad maltratada horriblemente por la lanza de Papini. Desde luego, el prestigio de $\mathrm{Pa}-$ pini no se amengua, poniendo en claro sus defectos temperamentales. Papini ha podido ser todo lo exhibicionista o escandaloso que se quiera. Se destruiría, en cambio, ese prestigio si se demostrara que su obra es absurda, contradictoria o sofística. Después de todo, no se puede acusar a un escritor de que escribe mucho; ni a un hombre viejo de que, a pesar de los años, permanece joven. Por otra parte, nunca han sido los buenos críticos del agrado de los autores; geniales o mediocres, han preferido estos últimos el halago cortesano o la condescencia cómplice.

(6) Las partes principales de la polémica fueron publicadas por la Revista de América (Bogotá, Colombia, 1947).

(7) "La capacidad imitativa de los suramericanos es tan amplia, como limitada su facultad de representación y de imaginación". Meditaciones Suramericanas, Hermann Heyperling, pág. 330. 